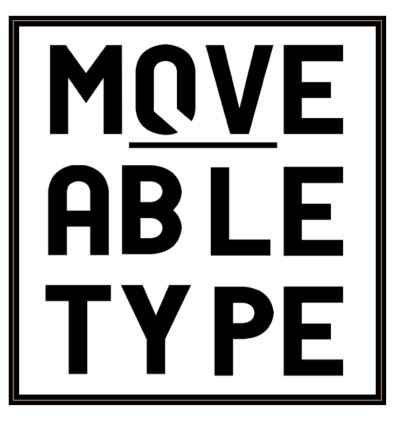

'Ambient Literature: Textuality and Narratology'

Author: Urvi Shah

Source: Moveable Type, Vol.13, 'Ambience' (2021)

DOI: 10.14324/111.1755-4527.119

MoveableType is a Graduate, Peer-Reviewed Journal based in the Department of English at UCL.

(C) 2021 Urvi Shah. This is an Open Access article distributed under the terms of the Creative Commons Attribution License (CC-BY) 4.ohttps://creativecommons.org/licenses/by/4.0/, which permits unrestricted use, distribution, and reproduction in any medium, provided the original author and source are credited.

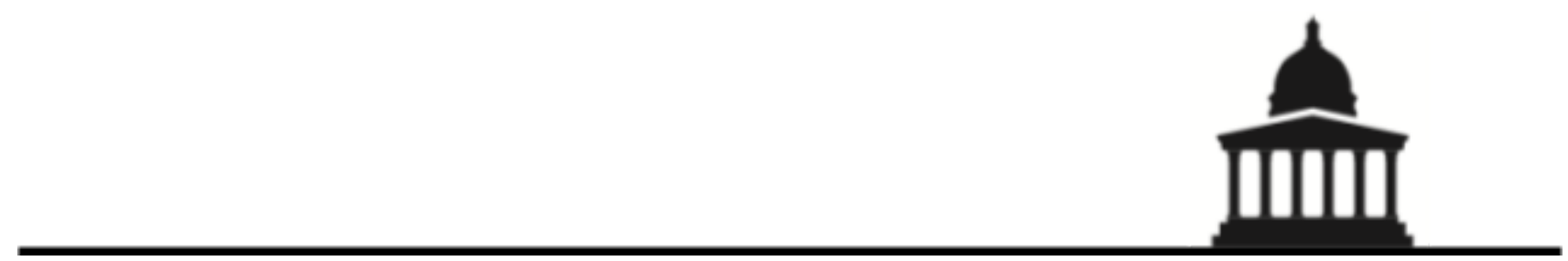




\title{
Ambient Literature: Textuality and Narratology
}

Urvi Shah

\begin{abstract}
Ambient Literature: Towards a New Poetics of Situated Writing and Reading Practices. Edited by Tom Abba, Jonathan Dovey and Kate Pullinger. 2021. xii + 337p. £103.99. Palgrave Macmillan. ISBN 978-3-030-41455-9
\end{abstract}

Late twentieth-century machines have made thoroughly ambiguous the difference between natural and artificial, mind and body, self-developing and externally designed, and many other distinctions that used to apply to organisms and machines. Our machines are disturbingly lively, and we ourselves frighteningly inert. ${ }^{1}$

Donna Haraway, Manifestly Haraway, 2016.

In 1964 Marshall McLuhan wrote 'the medium is the message' in The Extensions of Man in order to argue that the medium is not just a channel in which communication takes place but an extension of human consciousness. ${ }^{2}$ The reliance on digital devices that is evinced across much of the world today demonstrates the insight of McLuhan's aphoristic observation: humans and media work in coordination with one another, manipulating our perception of time and space. Set within this context of hybridization, Ambient Literature: Towards a New Poetics of Situated Writing and Reading Practices (2020) carves out a niche for itself by discussing literature in which the fictional element is governed and mediated by technology, while the medium controls and creates the progress of the narrative. ${ }^{3}$ In these works human experience is enmeshed within 'cybernetic circles of information loops' and generated by interaction with 'human data' (4).

The Ambient Literature Project, which seeks to create and codify location-based reading experiences with the help of technology, marked another watershed moment in the history of

\footnotetext{
${ }^{1}$ Donna J. Haraway, Manifestly Haraway (USA: University of Minnesota Press, 2016).

${ }^{2}$ Marshall McLuhan, Understanding Communication: The Extensions of Man (Canada: McGraw-Hill, 1964).

${ }^{3}$ T. Abba et al. (eds.), Ambient Literature (Switzerland: Palgrave Macmillan, 2021). Subsequent quotations will be cited parenthetically in the text.
} 
the book. By creating literature that could, for instance, be accessed entirely through an app on a mobile device while a 'reader' walks around the city, the project demonstrated how literary texts can be created on-the-go in a mutable, personalised fashion. These apps rely on a specific form of human-technological partnership in which the reader's surroundings operate as a contextual medium integrated, interfaced, and altered by the technological software and the reader's unique interaction with it.

Ambient Literature, as a critical accompaniment tracing the trajectory of the earlier project, archives its elusive digital texts (many of which are no longer accessible to the public) and provides a manifesto for ambient literature, presenting a critical and interdisciplinary framework that demands recognition of the modes of reading that rise to meet 'smart-text' ${ }^{4}$ It also provides case studies of Kate Pullinger's interactive browser-based narrative Breathe (2018), James Attlee's geo-located app The Cartographer's Confession (2017), and Duncan Speakman's book and audio experience It Must Have Been Dark by Then (2017) to show how these digital stories thrive on the spontaneous, unpredictable, and uncontrollable elements of the reader's (or the user's) immediate surroundings. By making the story unfurl in the place, hour and climate in which the reader is present, both reader and digital text cooperatively articulate the outcomes.

This temporal focus requires critics to adjust to a new paradigm in which the physical act of reading is merged with firsthand experience of the events in the text. This concept of ambient literature thus extends Brian Eno's concept of the ambient as something that is 'as ignorable as it is interesting' because the story-and the reader's situated role within it-has the potential to give agency to otherwise 'ignorable' elements of daily life by drawing them into the hybridized narrative networks of these stories (2)..$^{5}$ Alongside technologically-driven ambience, experience

\footnotetext{
${ }^{4}$ Smart-text refers to text created by technology and embedded in the internet.

${ }^{5}$ Eno, B., R. Wyatt, R. Davies, C. Fast, C. Gomez, and I. Zeininger. Ambient. 1. Music for Airports. Virgin Records.
} 
emerges as a framing concept because each of the commissioned stories contains 'memory, history, place-based writing, hallucination, and drama, as well as reworking of traditional forms of narrative including the novel, cinematic and audio storytelling' (1). A notable example of the storytelling feats achieved by ambient literature is Pullinger's Breathe. Intended to be read on a smartphone web browser, this ghost story follows Flo, a young woman who can communicate with the dead. Flo's fiction merges with the reader's reality: as the reader sits and receives Flo's story through their smartphone, location-specific information about the reader and their surroundings is fed from the phone into the story.

Ian Gadd's analysis of Breathe draws parallels between books and smart-text, pointing out instances where entities of the book, reader and story combine into one, intensifying the reader's immersion in the text. In 'Ready Reader One: Recovering Reading as an Ambient Practice' Gadd traces the displacement and disembodying of the reader within the long history of Western novel-reading practices (30). Gadd is attentive to the technical aspects of reading such as handling the book as an object, public and private reading, and the altered relationships between book and reader when the digital reconfigures the haptic experience. Yet he also suggests that reading in any form and at any given point of time has always been a situated and ambient act. His chapter creatively presents St. Augustine's writings as predecessors to Breathe as both redefine the nature of textuality and present a 'readiness' or willingness on the part of the reader to be absorbed into the narrative. Through this comparison, Gadd reclaims the historical status of embodied and situated reading and presents Breathe as a re-orientation and re-working of traditions.

Though an acknowledgement of the historical longevity of these issues is pertinent, a caveat remains as to whether ambient literature as a genre only extends and amplifies features

1978. 
of conventional reading rather than contributing anything new. In his attempt to address this issue, Gadd negotiates the slippery slopes between novelty and innovation, and a restructuring of form. While ambient texts reform our idea of reading and the perception of texts, they also modify factors such as the sedentary and stationary nature of traditional reading, in favour of the creation of texts on-the-go. Perhaps, most profoundly, ambient literature can be defined as a non-conventional form of reading-experience that restructures the fictional form of the past through innovation of human-device interaction.

The concept of 'attention' that Gadd sketches is elaborated by Michael Marcinkowski's 'Developing Ambient Attention' which defines ambient attention as a mix of psychology on one hand, and social practices, cultural norms, and historical traditions of the reader, on the other (115). He writes, '... the structure of attention in these works is given a hermeneutical rendering, with attention having its effect in its movement between attention and distraction, leaving the participant, and not the work itself, to be the locus of meaningful action' (116). Ambient literature as a cultural object is thus largely dependent on attentiveness and inattentiveness which stems from the reader's embodied situation, and also lays stress on the relationship between attention and distraction in the process of one's experience of these texts. He further notes two hermeneutic models of attention. The first is rooted in the ambient music of Eno by which 'attention might go out to the surrounding world and back toward the work itself in order to create a more satisfying experience' (128). The other is the formation of 'ambient intelligence' as a result of ubiquitous computing entering into everyday life (129). Though these appear to be tenuous theories in their abstraction, Marcinkowski shows how these models manifest themselves in Breathe in which a reader's attentiveness interacts with their experience as well as technology. Consequently, readers are not just made to be a part of the narrative but also actively create one that is exclusive to them. 
In 'What We Talk About When We Talk About (Ambient Literature) Context' Marcinkowski raises a question about the kind of context that ambient literature inhabits and answers his own question by using James Attlee's The Cartographer's Confession as point of reference. In Attlee's work the fictional setting is that of mid-twentieth century London but, while experiencing the narrative, readers have to explore the spaces within the city of London in real time. Hence, these two contexts of past and present work in tandem and as a result 'create a third, hybrid context within which the experience of the work exists' (55). He argues that ambient context is made through the interaction of technology, environment, history, social practices, and lived experience which in turn adds meaning to texts like The Cartographer's Confession and It Must Have Been Dark by Then. The correlation he draws between existing contexts (as provided by the smart-text) and the newer contexts (being created while the story is in progress) not only analyses the circumstantialities of the reader and the text but also complements the aspect of ambient attention that is derived from this contextual milieu.

That ambient literature is a specific example of wider trajectories of communication and human-technology interface is further substantiated by Matt Hayler's 'Objects, Places and Entanglements'. In this chapter Hayler establishes reading as an entangled act. His thesis withdraws or complicates or enmeshes the domains of meaning-making from both the author and reader by examining the way in which intention, action, and cognition are always shaped by mediation, and the act of reading and deciphering ambient texts are guided by technology (80). Ambient literature, thus, unites the human (readers) and non-human (gadgets) giving way to dependency of one on the other. Such entanglement or association between a human and device generates meaningful texts although the dependency on technology is not quite discernible. The experience of these texts is not just for the purpose of entertainment or mere fictionalization but indicates the presence of a critical awareness of one's surroundings and social reality, as ambient literature never aims to offer a parallel fictional universe, rather utilises the aspects of one's 
immediate surroundings, heighten the reader's attention, in order to show our shared realities (141). Dovey and Hayler's chapter 'Critical Ambience' notes that technology, connectivity, and reader-awareness assist in the critical understanding of embodiment, textuality, and space, and the shared world at large (158). This chapter segues well with all the previous discussions about attention, context, entanglement, ubiquity, and immersion, providing a critical base to not just the ambient texts but also the central argument of the book regarding the establishment of Ambient Literature as a new kind of reading experience.

Haraway's characterization of the late twentieth century as 'a mythic time'-where 'we are all chimeras, theorised and fabricated hybrids of machine and organism... a condensed image of both imagination and material reality'-reflects on the work and ambition of place-inflected writing. ${ }^{6}$ The ambient literature of the twentieth century is the practical manifestation of this synergistic fusion and how it develops in the twenty-first century. The book is a detailed guide to an understanding of the theoretical and critical aspects relating to this category of literature which requires application of digital tools and human computing. It extends its textual analysis of creative works of authors associated with the Ambient Literature Project to encompass consideration of political aspects such as gender, sexuality, disability, race, and class. In addition to critical chapters, the book also provides artist interviews of Duncan Speakman, James Attlee, and Kate Pullinger, each of which validates the theories set forth by the contributors of the collection of essays. Their personalised accounts of the motive behind formulating these texts will act as a point of reference for future discussions and study.

The concluding chapters on narrative formation, style and structure by Emma Whittaker, Amy Spencer, and Tom Abba build on the previous ones; hence, the book progresses from theoretical definitions, characteristics, and features of ambient literature to a more practical and

\footnotetext{
${ }^{6}$ Donna J. Haraway, “A Cyborg Manifesto: Science, Technology, and Socialist-Feminism in the Late Twentieth Century in Simians, Cyborgs and Women: The Reinvention of Nature (New York: Routledge, 1991).
} 
technical aspect of composing the texts. Abba and Amy Spencer's 'Writing Ambient Literature' associates ambient texts with a performance text because it operates on a temporal form, for a specific length of time, and through interaction and physical location (290). They agree that performance, though not the principal aim, becomes an intrinsic part of the text and the experience of it, and most importantly it transforms and transcends the boundaries of the page (293). Before this, Marcinkowski has compared It Must Have Been Dark by Then and The Cartographer's Confession to theatre performances (216). Hayler has commented on performance entanglements, connecting the immersive experiences of live performances with that of ambient texts (142). Emma Whittaker in 'Writing Ambient Literature' writes that ambient poetics consists of the seven features of 'embodied reading, movement, reflexive technology, performance, textual space, unpredictability and temporality' (277). Ambient literature wants to create 'a space' for the reader 'to think' so they actively participate in narrative-making. Despite similarities to performance art in terms of temporality, duration, composition, and experience, ambient texts go further in collapsing performer and reader/audience distinctions in the midst of the narrative, so that neither remain restrained in the position of creating or receiving the text.

Ambient literature literally, symbolically, metaphorically, spatially, and temporally breaks the fourth wall, offering newer dimensions to works of art, where the reader is not only involved but actively participates in creation of the text and plot progression. It calls into question the very definition of a book, transporting the tactile and imaginary to broader levels of sense perception. Sufficient as a preliminary companion to a new field of digital literature, one would expect more discussions and deliberations regarding ambient literature and psychoanalysis, the theatricality of it, and whether it is a threat to the book as an object or a continuation of it. 
Moveable Type 13 